\title{
ARTIGO
}

\section{OS MOVIMENTOS DE CULTURA E EDUCAÇÃO POPULAR: ESCRITAS DE UMA HISTÓRIA ${ }^{1}$}

The movements of culture and popular education: writings of a history

Los movimientos de cultura y educación popular: escritas de una historia

Kergilêda Ambrosio de Oliveira Mateus Universidade Estadual do Sudoeste da Bahia - Brasil

Aida Victória Garcia Montrone Universidade Federal de São Carlos - Brasil

\section{Resumo}

Neste trabalho, por meio de um estudo bibliográfico, trazemos algumas análises sobre a constituição dos distintos conceitos referentes à Cultura e Educação Popular no transcurso da história. O objetivo desse estudo é refletir sobre a importância dos movimentos de Educação Popular no Brasil e a atualidade das suas demandas, enquanto práxis de resistência e rebeldia à ordem social opressora ainda em curso. Em decorrência dos novos espaços de atuação dos sujeitos que constroem a Educação Popular apontamos a conformação de um Campo Popular onde se aglutinam distintas temáticas, mas que se interseccionem com a busca da transformação das relações de opressão sofridas por sujeitos individuais e/ou coletivos das classes populares.

Palavras-chave: Campo popular. Cultura popular. Educação popular.

\begin{abstract}
This paper aims to analyze about the constitution of multiple concepts that reference to culture and popular education in the history. The purpose of this study is to reflect on the importance of Popular Education movements in Brazil and the actuality of their demands, as a praxis of resistance and rebellion to the oppressive social order still in progress. As a result of the new spaces of action of the individuals who construct Popular Education, we point to the conformation of a People's Field where different themes intersect but intersect with the search for the transformation of the relations of oppression suffered by individual and / or collective Popular class.
\end{abstract}

\footnotetext{
1 O presente texto é um recorte da tese de doutorado, intitulada: "Modos de vida e convívio escolar: o Assentamento Rural Santa Helena, São Carlos, São Paulo", defendida em junho de 2016, no Programa de PósGraduação em Educação da Universidade Federal de São Carlos (UFSCar).
} 
Keywords: Popular field. Popular culture. Popular education.

\section{Resumen}

En este trabajo, a través de un estudio bibliográfico, traemos algunos análisis sobre la constitución de los distintos conceptos referentes a la Cultura y la Educación Popular en el transcurso de la historia. El objetivo de este estudio es reflexionar sobre la importancia de los movimientos de Educación Popular en Brasil y la actualidad de sus demandas, mientras que las práxis de resistencia y rebeldía al orden social opresivo aún en curso. En consecuencia de los nuevos espacios de actuación de los sujetos que construyen la Educación Popular apuntamos a la conformación de un Campo Popular donde se aglutinan distintas temáticas, pero que se interseccionen con la búsqueda de la transformación de las relaciones de opresión sufridas por sujetos individuales y / o colectivos de las clases Populares.

Palabras clave: Campo popular. Cultura popular. Educación popular.

\section{Cultura e Educação Popular: itinerâncias conceituais e espaços de luta}

Os movimentos de cultura e educação popular ganharam força e expressão na sociedade brasileira e influenciaram diversas práticas e debates em vários países do continente latino americano, a partir do final da década de 1950 e início de 1960. Ao discutirem o papel educativo da cultura no processo de conscientização da classe oprimida e a superação das suas condições materiais por meio da transformação da sociedade, buscavam tornar essa realidade menos hierárquica, onde existisse "menos privilégios para as minorias dominantes e menos miséria para as maiorias dominadas" (BEISIEGEL, 1986, p. 64).

O clima mundial pós-guerra e a queda do regime autoritário de Vargas, fez renascer a esperança de se consolidar a democracia no país e contribuiu para a nova conjuntura política e social que se estabeleceu no Brasil a partir de 1945.

Nessa época, o desenvolvimento social já alterara profundamente as condições de vida na região: invertiam-se as posições numéricas da população nas áreas rurais e urbanas; mudava a estrutura do mercado de trabalho; multiplicavam-se as oportunidades de emprego em atividades urbanas não-manuais; as expectativas de ascensão social segundo padrões característicos da moderna sociedade industrial iam progressivamente alcançando setores cada vez mais amplos da coletividade. (BEISIEGEL, 1979. p. 43-44).

A industrialização que se efetivava transformava o cenário da sociedade brasileira ao promover uma forte migração das populações rurais para os centros urbanos, por meio de um processo de fortalecimento do capitalismo que promovia a gradativa desintegração dos modos de vida das comunidades rurais que precisaram buscar outros espaços para se estabelecer. A 
partir desse processo migratório, a visibilidade das precárias condições em que viviam os homens e mulheres do campo quanto ao difícil acesso à educação escolarizada, à saúde e direitos trabalhistas, fica ainda mais evidenciada e as demandas para melhorar o nível de escolarização e formação dessa população geram pressões dos vários setores urbanizados e de empresários que necessitavam dessa mão de obra para atender aos seus interesses de mercado.

Se, de um lado, a educação de adultos e o desenvolvimento de comunidades marginalizadas eram um direito e um benefício social, de outro lado, eram também um investimento, porquanto pretendiam ser processos sistemáticos e meios participativos de integração de contingentes de pessoas e grupos postos "à margem", no interior do mercado de trabalho, no pleno exercício da cidadania e no desenvolvimento da sociedade. (BRANDÃO; ASSUMPÇÃO, 2009, p. 22-23).

Faz-se necessário sublinhar que as grandes migrações rurais para os espaços urbanos ou mesmo de pessoas que viviam em estados localizados na região Nordeste para as regiões Sul e Sudeste do Brasil, representava um enorme problema social para as classes dominantes política e economicamente, tanto dos setores urbanos quanto dos rurais, pois refletiam diretamente nas suas relações de exploração da força de trabalho e os lucros adquiridos nessas relações, gerando preocupações com esse fenômeno e posicionamentos contrários que apontavam a migração como grande problema social do país.

O grito alarmado contra o êxodo tinha duas proveniências bem claras: de um lado, os grandes proprietários de terra, preocupados com a perda da mão-deobra barata ou, até, gratuita que ocupavam em suas fazendas. De outro lado, grupos urbanos, particularmente a classe média, assustados com o crescimento da população pobre nas cidades, a mendicância, a delinquência e outros problemas daí decorrentes. Entre os problemas, a perda da tutela política dos grandes proprietários sobre os trabalhadores rurais e, na cidade, a ação política dos comunistas sobre os trabalhadores imigrados. (MARTINS, 2009, p. 39).

Como fenômeno que se mostrou irreversível, a migração que caracterizou o período impeliu a classe dirigente a adotar medidas que minimizassem o impacto nas relações de poder e atendessem a algumas demandas que emergiram, dentre elas, a educação escolarizada. A partir de tais demandas e tomando como principal objetivo o fortalecimento do sistema capitalista por meio do estabelecimento de outras formas de relações de trabalho que teve como base o operariado industrial, programas e projetos de educação passaram a fomentar a formação dessa mão de obra em nome de um discurso vinculado ao progresso e desenvolvimento do país. 
Interesses e pressões de setores urbanizados da população brasileira, ao lado das vantagens que o empresariado via em uma melhoria do nível escolar e da capacitação da força de trabalho de migrantes rurais ou estrangeiros reunidos em suas indústrias foram também fatores muito importantes. (BRANDÃO; ASSUMPÇÃO, 2009, p. 15).

A superação do analfabetismo e a expansão da rede escolar passaram a fazer parte das reivindicações de diversos segmentos sociais e pressionaram o poder Federal a implementar campanhas de alfabetização que buscavam ensinar as primeiras letras a população, em sua grande maioria, proveniente do meio rural. Essas ações evidenciam a preocupação do poder central em melhorar os índices e atender aos interesses do mercado de trabalho, sem, entretanto, promover uma real transformação das condições de trabalho e melhoria de vida dessas populações, conformando esses homens e mulheres as estruturas que lhes eram impostas. A esse respeito Brandão e Assumpção (2009) sublinham dois princípios presentes nos ideários educacionais do período,

O primeiro: a educação escolar era não só um direito de todos os cidadãos, mas o meio mais imediato, justo e realizável de construção das bases de uma sociedade democrática. O segundo: modificações fundamentais nas formas e na qualidade da participação de inúmeros brasileiros, tanto na cultura quanto na vida econômica e política do país, eram uma condição fundamental para a melhoria dos indicadores de nossa situação de atraso e pobreza (BRANDÃO; ASSUMPÇÃO, 2009, p. 17-18).

Dentro dessa concepção de pobreza e atraso atribui-se às camadas populares uma enorme parcela de responsabilidade por esses fatores, visto que não fazem parte do contingente de pessoas que tem se apropriado dos saberes institucionalmente credenciados pela sociedade e que são considerados pré-requisitos fundamentais para a sua aceitação e consequente inserção nas frentes de trabalhos não-manuais, aos quais são creditados os méritos para se atingir o desenvolvimento e progresso, em um flagrante desprestígio ao trabalho como valor de uso social em benefício deste como valor de troca.

A escola pública foi vista como espaço capaz de redimir esse processo de atraso que vivia o país, bem como a saída para minimizar as desigualdades sociais características da sociedade brasileira, o que deflagrou inúmeros movimentos que reivindicavam o acesso à educação pública, universal e gratuita.

Tais reivindicações estiveram presentes desde as reformas dos sistemas de ensino estaduais no início do Século XX, onde se propunha uma educação popular - concebida como ensino gratuito e universal da escola pública - a todos os setores e camadas sociais, e atingiu maiores proporções nesse período pós-ditadura. Essa forma de se conceber e propor uma 
educação destinada às classes populares, não cumpriu satisfatoriamente sequer com seu intuito mais elementar de alfabetizar as crianças, jovens e adultos e inserí-los no mercado de trabalho.

Essa educação popular, todavia, pouco mais conseguiu oferecer às classes populares que um ensino facilitado para as crianças e de segunda mão para os adolescentes e adultos - porque reduzido à alfabetização nas classes de emergência e à iniciação profissional nos cursos supletivos noturnos. (FÁVERO, 1983, p. 8).

Em contraposição a ações educativas que buscavam a conformação das classes populares a um modelo de sociedade cada vez mais hierárquico e desigual, onde as condições de opressão e exploração tornavam-se mais complexas e a formação do povo direcionada para atender a uma demanda de mercado, começa a ser constituído no Brasil, no início dos anos 1960, o movimento de cultura e educação popular caracterizado como ações teóricas e práticas de, por meio da cultura que emerge do povo, promover processos educativos que levassem à conscientização crítica e, a partir dela, à transformação da sociedade. Dentro dessa abordagem,

A educação popular é um movimento prático e teórico em educação, presente em processo de organização das classes trabalhadoras, sobretudo, que apresenta profunda crítica à educação dominante e que, segundo Paulo Freire (1985), tem promovido o 'silêncio' dessas maiorias, defendendo outro fazer educativo - educação popular -, definido por uma educação com o homem, e não sobre o homem, ou, simplesmente, para ele. Uma educação promotora de mudanças e criadora de outras novas disposições mentais no humano, enquanto coloca-o na sua contextura sócio-cultural, em condição compreensiva de seu mundo. (MELO NETO, 2010, p. 1).

Nessa perspectiva, a educação popular emerge como movimento comprometido com a emancipação da classe oprimida, por meio de um trabalho político que buscava transformar o sistema social e o próprio sistema de ensino a ele vinculado. Nesse processo de desvelamento dos arranjos de manipulação e alienação ideológica usados por grupos opressores e que teve, em uma determinada forma de educação escolarizada, um veículo potente para inculcação de uma ideologia que objetivava a perpetuação da ordem social vigente, surgiram algumas experiências educativas que propuseram a ruptura com essa forma de se fazer escola denunciando o seu caráter "bancário" que levava os seus participantes a uma postura passiva diante da sua própria aprendizagem e consequentemente diante do mundo.

A criação de espaços de práticas políticas populares que foram desenvolvidas em distintos contextos e que ultrapassavam os muros das escolas, caracterizaram a época como de 
grande riqueza na produção de ações alternativas para promoção de uma educação que, surgindo do povo, para ele retornasse re-significado e a partir dessa re-significação promovesse uma nova leitura do mundo e a assunção dos seus participantes como sujeitos ativos no processo histórico. O testemunho de Brandão (1986b) nos ajuda a compreender a riqueza teórica e prática desse momento histórico e suas produções.

\begin{abstract}
A década de 1960, que nos envolveu a todos com a educação popular, foi o tempo de uma verdadeira reinvenção da criatividade e do compromisso da educação no Brasil. A produção do Método Paulo Freire dentro do Serviço de Extensão Cultural da Universidade Federal de Pernambuco; as experiências duradouras de uma "educação conscientizadora" entre lavradores de Minas Gerais para cima e para o oeste, através do Movimento de Educação de Base; a multiplicação de trabalhos culturais e pedagógicos feita pelos Movimentos de Cultura Popular (MCPs) e pelos centros populares de Cultura (CPCs), promovidos pela UNE e outras entidades regionais e locais do estudantado brasileiro; a montagem do Programa Nacional de Alfabetização, pelo Ministério de Educação e Cultura. (BRANDÃO, 1986, p. 12).
\end{abstract}

Esses, dentre outros movimentos da época, se desdobraram em teorias e ações que denunciavam os processos de negação dos direitos e de acesso aos conhecimentos institucionais a uma significativa parcela da população brasileira, bem como anunciavam novas formas de organização das classes populares e o seu empoderamento para romper com a realidade opressora vivenciada e transformar as estruturas sociais vigentes.

Ao denunciar o caráter bancário ${ }^{2}$ que caracterizava as práticas escolares vigentes no período, Paulo Freire surge como expoente de um novo jeito de trabalhar com o processo de alfabetização de adultos, partindo da realidade existencial desses sujeitos com o objetivo de promover uma leitura de mundo crítica e de desvelamento da realidade marcada pela desigualdade e opressão. Ao defender a concepção do homem e da mulher como seres de relações que não apenas estão no mundo, mas com o mundo em um processo de apropriação e criação deste, Freire (2005) denuncia o caráter de desumanização presente na tentativa de suprimir a liberdade humana por meio da aceitação da realidade, que o direciona à acomodação e ao ajustamento e consequentemente à negação deste de perceber-se como sujeito que interfere no mundo e o cria.

\footnotetext{
${ }^{2}$ Para melhor compreensão e aprofundamento do que Freire denuncia como Educação Bancária e que serve de crítica a forma como se estabelece a relação entre a escola e os grupos populares e os seus desdobramentos nos processos de silenciamento e alienação, bem como a sua proposição de uma educação libertadora, sugerimos a leitura das obras do autor: Educação como Prática da Liberdade (2005) e Pedagogia do Oprimido (2011).
} 
Por isso, toda vez que se suprime a liberdade, fica ele um ser meramente ajustado ou acomodado. E é por isso que, minimizado e cerceado, acomodado a ajustamentos que lhe sejam impostos, sem o direito de discutilos, o homem sacrifica imediatamente a sua capacidade criadora. (FREIRE, 2005, p. 50).

A consciência da sua capacidade criadora possibilita homens e mulheres a tomarem para si a escrita da própria história, abandonando sua condição de meros espectadores ou coadjuvantes, mas protagonistas, autores e fazedores dela. Desafiados por uma inconclusão que os caracteriza, se percebem capazes de construir um outro futuro ainda não determinado, mas em processo constante de modelagem à espera das ações criativas dos artífices - todos nós - responsáveis por essa arte inacabada.

A conscientização crítica é considerada elemento fundamental das ideias freireanas, "são os estados da consciência a área privilegiada de sua reflexão" (WEFFORT, 2013, p. 24), pois a partir dela os sujeitos podem refletir sobre sua realidade, compreender as estruturas sociais vigentes como modos de dominação e violência, e por meio do engajamento na luta, transformá-la.

Ancorado nos ideários de liberdade como caráter ontológico de homens e mulheres, Freire desenvolveu uma prática de alfabetização de adultos que teve como marco alfabetizar 300 trabalhadores em cerca de 45 dias. Realizada na cidade de Angicos, Rio Grande do Norte em 1962, essa experiência impressionou a opinião pública, influenciou muitas ações do período e serviu de base a diversas encaminhamentos dos movimentos de cultura e educação popular.

$\mathrm{O}$ respeito aos homens e mulheres como portadores e fazedores de culturas, como sujeitos historicamente situados, integrados no e com o mundo, participantes da sua construção, constituiu-se elemento fundamental da prática pedagógica desenvolvida por Freire que influenciou e se fez presente nas ações dos Movimentos de Cultura Popular, Centros Populares de Cultura, "De pé no chão também se aprende a ler", dentre outros, que marcaram o período. A partir da leitura crítica do seu mundo e dos conhecimentos que daí emergem se faz possível a interferência consciente neste e a luta por sua transformação, na busca incessante pela liberdade.

A compreensão desta pedagogia em sua dimensão prática, política ou social, requer, portanto, clareza quanto a este aspecto fundamental: a ideia da liberdade só adquire plena significação quando comunga com a luta concreta dos homens por libertar-se. Isto significa que os milhões de oprimidos no Brasil - semelhantes em muitos aspectos, a todos os dominados do Terceiro 
Mundo - poderão encontrar nesta concepção educacional uma substancial ajuda ou talvez mesmo um ponto de partida. (WEFFORT, 2013, p. 15).

A efervescência do período político, marcado por várias formas de mobilização que buscavam denunciar os processos históricos de opressão, propiciar a participação popular nas arenas de decisão e a consequente transformação dessa realidade, gerou a reação dos grupos conservadores que viram o seu poder e hegemonia política ameaçados e deflagraram, em 1964, o golpe de estado que instaurou o mais longo período de ditadura e cerceamento aos direitos políticos da história. "O Golpe de Estado teve entre seus resultados (e também entre seus objetivos) a desestruturação deste que foi o maior esforço de democratização da cultura já realizado no Brasil" (WEFFORT, 2013, p. 15).

Apesar das perseguições promovidas pelo regime ditatorial que limitaram o poder de atuação dos militantes vinculados aos setores populares, as experiências realizadas pelos movimentos de cultura e educação popular não fracassaram, continuaram a acontecer em vários espaços, pois a semente plantada germinou e seus frutos são percebidos e reconhecidos no decorrer da história e servem como referência a novas proposições que lutam por uma sociedade mais equitativa e um mundo emoldurado pela solidariedade, respeito e amor.

Ficou a semente. Ademais, a experiência teve êxito porque - apesar de sua especificidade nacional e de sua conexão com uma etapa determinada da história brasileira - pode hoje começar a ser estudada em sua significação mais ampla, que transcende os marcos deste período e as próprias fronteiras do país. (WEFFORT, 2013, p. 15-16).

Os anos que se seguiram foram marcados por perseguições, prisões, exílios, torturas e desaparecimentos de muitos militantes e/ou simpatizantes ligados ao projeto de um país democrático e popular, mas também por movimentos de resistência e luta pela reabertura política do Brasil, que começou a acontecer no início dos anos de 1980.

Aquilo a que se configurou historicamente como Movimento de Educação Popular deparou-se com novas demandas, pois como característica fundamental de estar situado na história e com ela partilhar modos de ser, estar e fazer dos grupos oprimidos, precisou se reinscrever no novo momento e se reinventar dentro da dinâmica complexa que caracterizou os tempos pós-golpe e durante a vigência do período da ditadura civil-militar. Dessa maneira revalida a sua importância, torna atual as suas bandeiras de lutas e a urgência da sua análise e discussão em tempos onde a naturalização da fome, da miséria e do sofrimento são 
considerados por muitos como obra do destino ou opção daqueles que não tiveram o "esforço necessário" para vencer na vida.

As demandas sociais, culturais e políticas da nova conjuntura passaram a requerer da Educação Popular uma nova configuração que agregasse elementos que passaram a fazer parte das discussões e lutas de grupos historicamente alijados de direitos e/ou marginalizados na sua constituição. Dessa forma é preciso situar os conceitos que acompanham a sua trajetória e buscar proposições que a caracterizem no novo contexto.

\section{Educação popular: concepções inscritas na sua trajetória}

A educação das massas, enquanto característica que marca uma parte significativa daquilo que se tem considerado historicamente como educação popular, ou educação destinada às classes populares, tem suas raízes e ganha relevância com o advento da Reforma Protestante na Europa, que identificou a alfabetização como pré-requisito fundamental para leitura e interpretação pessoal da Bíblia e fortalecimento dos seus ideais. Aqui temos como concepção de educação popular a propagação das escolas de ler e escrever (PAIVA, 1986).

No caso do Brasil muitos conceitos foram atribuídos à Educação Popular no decurso da história. Brandão (2009) aponta que essa terminologia aparece pela primeira vez quando Fernando Azevedo descreve como embrião dessa educação o ensino escolar ministrado pelos jesuítas às crianças brancas, índias e mestiças, entretanto, "com exceções, o trabalho pedagógico escolar dirigido a índios, negros e brancos pobres foi restrito e provisório durante todo o período colonial" (BRANDÃO; ASSUMPÇÃO, 2009, p. 13). O autor nos faz aferir, a partir dessa afirmação, que a origem da concepção de educação popular está vinculada àquela que tinha como base a catequese de crianças e que, ainda assim, limitada a alguns poucos brasileiros.

Uma outra abordagem presente na história relativa ao conceito de educação popular, aparece no trabalho desenvolvido por Paiva nos anos de 1960 a 1970, quando disserta sobre a História da Educação Popular no Brasil onde atribui a essa terminologia o seguinte conceito:

Entende-se por educação popular, frequentemente, a educação oferecida a toda a população, aberta a todas as camadas populares da sociedade. Para tanto, ela deve ser gratuita e universal. Outra concepção da educação popular seria aquela da educação destinada às chamadas "camadas populares" da sociedade: a instrução elementar, quando possível, e o ensino técnico profissional tradicionalmente considerado, entre nós, como ensino "para desvalidos". (PAIVA, 2003, p. 56). 
Percebe-se que a ampliação e o acesso à educação escolarizada no nível elementar por meio da difusão do ensino primário, bem como a diminuição dos altos índices de analfabetismo que marcavam o período, fazem parte das demandas da época e influenciaram a concepção e o conceito da educação popular. Uma forma de educação restrita aos espaços escolares, pensada e operacionalizada por aqueles que detinham o saber e destinadas àqueles que não tinham a apropriação de conhecimentos - as classes populares.

Para além dessa concepção e com base nas experiências desenvolvidas por Paulo Freire com os grupos populares durante os anos pré-ditadura, e a denúncia de uma educação elementar destinada a esses grupos com características bancárias ${ }^{3}$ a educação popular passa a ser compreendida como movimento que implica a participação das classes populares na sua constituição e que a sua consecução não está restrita aos espaços escolares, mas, por sua dinâmica de organização e prática, pode acontecer nos diversos nichos sociais.

A partir desses apontamentos, defendemos que "a educação popular emerge como um movimento de trabalho político com as classes populares por meio da educação" (BRANDÃO; ASSUMPÇÃO, 2009, p. 27). Enquanto movimento, propõe-se ao não imobilismo e não se deixa aprisionar a um método ou a uma única prática, sua base fundamental é a vida cotidiana e o tempo histórico, onde ganha sentido e alicerça suas proposições. Nas palavras de Streck "há na educação popular uma dificuldade inerente de enquadramentos e de certezas dada a sua vinculação orgânica com o movimento da sociedade (STRECK, 2013, p. 360). Daí decorre seu caráter de estar sempre buscando novas alternativas e meios de se reconstruir e revalidar suas lutas que tem como principal foco o trabalho com as classes populares para que estas assumam sua vocação de tornarem-se sujeitos livres e construtores de uma sociedade onde a humanização prevaleça em oposição à coisificação de homens e mulheres que os desumaniza.

A desumanização, que não se verifica apenas nos que têm sua humanidade roubada, mas também, ainda que de forma diferente, nos que a roubam, é distorção da vocação do ser mais. É distorção possível na história, mas não vocação histórica. Na verdade, se admitíssemos que a desumanização é vocação histórica dos homens, nada mais tínhamos que fazer, a não ser adotar uma atitude cínica ou de total desespero. A luta pela humanização, pelo trabalho livre, pela desalienação, pela afirmação dos homens como pessoas, como "seres para si", não teria significação. Esta somente é possível porque a desumanização, mesmo que um fato concreto na história, não é,

\footnotetext{
${ }^{3}$ Segundo Freire (2011b, p. 80-81), “em lugar de comunicar-se, o educador faz 'comunicados' e depósitos que os educandos, meras incidências, recebem pacientemente, memorizam e repetem. Eis aí a concepção "bancária" da educação, em que a única margem de ação que se oferece aos educandos é a de receberem os depósitos, guarda-los e arquivá-los".
} 
porém, destino dado, mas resultado de uma "ordem" injusta que gera a violência dos opressores e esta, o ser menos. (FREIRE, 2011b, p. 40-41).

Nesse sentido a Educação Popular reveste-se da esperança de tornar-se um dos caminhos possíveis onde, no seu percurso, os oprimidos possam transitar para uma consciência crítica e assim assumir sua vocação histórica e se engajarem na luta pela transformação da sua realidade concreta e objetiva. Dentro dessa perspectiva, para além do acesso à escola e os conhecimentos que nela são trabalhados, o movimento busca a construção de um outro espaço onde possam ensinar e aprender, construído pelas classes populares para atender as suas reais demandas.

Uma escola onde a formação humana no sentido lato substitua aquela voltada para atender ao mercado, presente no decurso da história e que tem contribuído para efetivar as relações de exploração da força de trabalho, hierarquizando e promovendo relações de opressão daqueles que detêm os meios de produção e fragilizando ações que podem promover a conscientização crítica dos oprimidos, ao praticar um ensino bancário e domesticador.

O sonho de uma outra educação, dentro e fora das instituições escolares, mobilizou intelectuais e pessoas ligadas aos grupos populares desde as experiências dos anos de 1960 e, apesar dos mecanismos de silenciamento postos em prática pelo governo militar durante o regime ditatorial, ele permaneceu vivo nas utopias que impulsionaram diversas ações na afirmação e luta pelos direitos dos grupos populares e busca pela melhoria de vida dessas populações. Assim, com base nos pressupostos teóricos e práticos da educação popular, muitas pessoas e coletivos tem assumido um posicionamento político e ético a favor dos oprimidos e desenvolvem projetos e ações nas diversas áreas de atuação: saúde, artes, educação, dentre outras, e buscam a superação das condições opressoras em que se encontra uma grande parcela do povo brasileiro.

Pela diversidade de estudos, ações, enfoques, análises, propostas e pressupostos que tem sido apresentados nos últimos tempos vinculados a educação popular, observa-se a necessidade de uma ressignificação e redimensionamento desse aporte teórico e prático para que atenda as novas demandas que requerem a articulação de temas específicos e distintos e que fazem parte da luta pelo respeito e dignidade humana, presentes nas reivindicações da educação popular e que a caracterizam como movimento dinâmico, inconcluso e histórico.

É o movimento da realidade e a transformação dos contextos, portanto, um dos fatores indicados pelos documentos e textos, que impulsionam a necessidade de ressignificação/refundamentação da Educação Popular, 
mostrando a indissociabilidade entre Educação Popular e processos históricos e sociais. (PALUDO, 2009, p. 45).

Ao buscar novos lugares de realização, as práticas de Educação Popular revitalizam as suas lutas e recriam novas e outras formas de atuação, tornando-se força pulsante ancorada no contexto histórico atual e vinculada as novas demandas que emergem em espaços plurais. Dessa maneira resistem as estratégias que tentam negar as suas formulações e práticas, bem como o alcance e atualidade das suas proposições, buscam no interior das contradições das relações opressoras, condições para se recriar e assim fortalece as marcas que a caracterizam: a resistência e a criatividade.

\begin{abstract}
Argumenta-se que, sendo a educação popular uma educação que se realiza nas margens da sociedade, essas margens não são fixas, nem geográfica nem institucionalmente. Como características das práticas aparece, por um lado, a capacidade de resistir dentro de uma realidade excludente e opressora e que é também resistência a essa realidade. Por outro lado, há expressões de criatividade que apontam para além da luta pela sobrevivência e podem ser vistas como indícios de outras formas de conhecer e conviver. (STRECK, 2013, p. 357).
\end{abstract}

Com as marcas da resistência e criatividade, as práticas de educação popular no nosso tempo readquirem novas configurações decorrentes das mudanças nas esferas sociais, culturais, econômicas e políticas desencadeadas pela nova ordem mundial do "Projeto da Modernidade" que se estabeleceu com o advento das novas tecnologias, onde são usadas estratégias de manipulação, alienação e opressão com maior poder de alcance e capilaridade. A esse respeito Paludo (2009, p. 44) nos adverte,

\footnotetext{
Sua atuação e influência sobre as sociedades é total e incide, ainda que para se viabilizar economicamente, na esfera da política, recompondo, principalmente, o papel do Estado e, na esfera da cultura, atuando fortemente para a formação de um novo senso comum, conformando comportamentos e subjetividades aderentes aos valores e necessidades requeridos pelo novo padrão de acumulação do capital.
}

Essa nova conjuntura mundial requer das práticas subversivas que buscam o rompimento com a lógica perversa do capital, e dentre elas aquelas ligadas a educação popular, novas estratégias de atuação e novos espaços para se reinscrever sem, no entanto, deixar de lado a essência que vitaliza as suas existências e que permanecem como elo entre as suas tradições e os novos desafios postos: a luta contra os processos que promovem as injustiças e as desigualdades e a busca de ações que possibilitem a formulação de uma humanidade livre em um mundo de justiça, igualdade e paz. 
A educação popular que historicamente esteve vinculada a grandes movimentos pelo acesso à educação, a favor da alfabetização, na luta pela liberdade, contra a ditadura e pela inclusão dos sujeitos pertencentes as classes populares submetidos a todos os tipos de escassez, alarga suas fronteiras e articula suas categorias discursivas as demandas atuais: gênero, religião, etnia, subjetividade, cotidiano, ecologia, ética, idade, nação/regionalidades/localidades, dentre outras, passaram a fazer parte das pesquisas e estudos realizados pela vertente popular.

Partindo dessa observação [...] sobre a vigência de categorias como "classe social" (ou "classe popular"), "trabalho", "luta de classes" e outras afins, tratemos agora de sustentar a necessidade de articulação dialética da categoria "classe popular" a várias outras de crescente importância na atual conjuntura. (CALADO, 1998, p. 141).

As articulações estabelecidas tornam-se fundamentais e serão consideradas ao nos referirmos as classes populares, pois em decorrência dos grupos e suas especificidades presentes nessa categoria, acreditamos que todas fazem parte de um grande processo histórico onde são vítimas de marginalização e opressão.

A partir da análise do percurso histórico e das várias concepções atribuídas à Educação Popular no seu transcurso, e com a intenção de nos aproximarmos de uma síntese que englobe as suas características no contexto presente e que venha a contribuir para a compreensão do seu conceito e proposições, nos apoiamos em Wanderley (2010) quando afirma que a Educação Popular é,

Uma educação de classe - exige um consciência dos interesses das classes populares; histórica - depende do avanço das forças produtivas; política - se conjuga com outras dimensões da luta global das classes populares; transformadora e libertadora - luta por mudanças qualitativas e reformas estruturais (reformas não reformistas); democrática - antiautoritária, antimassificadora, antielitista; relaciona a teoria com a prática; relaciona a educação com o trabalho; objetiva a realização de um poder popular. (WAMDERLEY, 2010, p. 23).

Tomando como base as suas características e possíveis conceitos que emergem delas, situamos a educação popular no presente e salientamos que os dilemas vivenciados por pessoas /coletivos/instituições locais ou regionais que assumem a vertente popular, não estão dissociados do contexto mais geral e ecoam por toda a América Latina e em países que sofrem com as políticas colonizadoras de dominação econômica, política e cultural. Nessas circunstâncias, e com a pretensão de englobar as diversas ações, propostas, estudos e temáticas desenvolvidas nos diversos contextos, tanto locais quanto continentais, e que 
possuem afinidades com as lutas populares por meio da visão social de mundo presente nas suas teorizações e práticas, conforma-se o Campo Popular como possibilidade de refundamentar e ressignificar a Educação Popular. Nesse sentido,

O Campo Popular [...] decorre de um pressuposto de análise da realidade que compreende a sua dinâmica como sendo posta em movimento pela interrelação entre uma quantidade significativa de forças que são políticas e culturais e se articulam conformando campos sociais, que sempre guardam relação com a esfera da economia. Estes campos possuem "visões sociais de mundo" que orientam tanto as teorizações da realidade, quanto as ações. (PALUDO, 2009, p.45).

As questões que interessam aos grupos e pessoas que trabalham com o popular, ancoradas em utopias transformadoras, atravessam as instituições, as organizações e os sujeitos que constituem os Campos Populares e que podem ser fortalecidos com o seu reconhecimento enquanto campo que se fundamenta em projetos de ruptura da ordem social e em proposições de um outro modelo de sociedade vinculado a emancipação e libertação de todos os homens e mulheres.

Os Campos Populares, constituíram-se como movimentos contrahegemônicos e orientaram-se por utopias de transformação social, às quais foram atribuídas as mais diversas denominações, dentre as quais se podem citar, a partir das leituras, como exemplos: projeto histórico; projeto libertador; novo contrato social; nova sociedade; sociedade justa, democrática, participativa e solidária; projeto alternativo de sociedade; sociedade sem oprimidos e opressores; sociedade socialista. (PALUDO, 2009, p. 46).

Enquanto esfera de produção de conhecimentos que se retroalimenta dos desejos de transformação social, o Campo Popular aponta como aspecto fundamental da sua ressignificação e refundação, o reconhecimento de elementos fundamentais para a emancipação humana que se fazem urgentes no nosso tempo e que podem ser produzidos nos diversos lugares sociais, por distintos sujeitos individuais e coletivos e por instituições que, mesmo tendo como pano de fundo, as questões econômicas e de classe, suas análises devem ultrapassá-las como forma de desvelar outras relações de poder existentes e que promovem a negação do outro. Nesse encaminhamento, o Campo abarca as relações de gênero, éticas, étnicas/raciais, geracionais, entre outras, que são transversais a todas as classes sociais e que podem gerar relações opressoras (PALUDO, 2009). 


\section{Considerações finais}

Percebemos, portanto, que o Campo Popular, configura-se na atualidade, por complexos elementos que requerem dos seus militantes uma análise de conjuntura ainda mais criteriosa, bem como uma postura crítica mais profunda diante dos sutis e cada vez mais fortes mecanismos de alienação que tentam conformar as estruturas de poder, nos levando à ideia mítica de que o sonho de transformação social acabou e que a autopoiese não nos é possível.

O caráter de resistência e rebeldia que acompanham historicamente as ações vinculadas ao Campo Popular se fazem ainda mais necessárias como forma de reacender as chamas da esperança e de buscarmos ações que nos conduzam a promoção de uma humanidade constituída pela solidariedade, pela paz e amor aos homens, às mulheres, às plantas, aos animais e a todos e todas onde pulsa a vida. Enquanto não conseguirmos concretizar esse mundo projetado nas nossas utopias, as práticas de educação popular continuam necessárias e urgentes, pois só os oprimidos podem libertar a si mesmos e aos opressores (FREIRE, 2011).

Na busca pela assunção do seu lugar dentro da sociedade e como processo de transformação do cenário de exploração a que estiveram submetidos no decorrer da história, sujeitos sociais coletivos tem, por meio das suas ações, apontado caminhos alternativos de se fazerem ouvir tomando como apoio os pressupostos dos Movimentos de Educação Popular, resistindo àqueles e àquelas que tentam impor uma visão unilateral da vida e que negam outras formas de ser e estar no mundo.

A partir dessas reflexões reafirmamos a atualidade da luta contra qualquer tipo de opressão e registramos a força pulsante, viva, presente na condição ontológica do homem e da mulher como ser livre, inacabado e construtor de uma história ainda em curso, que desejamos seja da assunção de uma sociedade menos desigual e hierárquica. Aqui reside o fundamento primordial da educação popular: a transformação da realidade e do mundo em um lugar mais tolerante, respeitoso, democrático e onde a vida seja moldada nos alicerces da solidariedade e do amor.

\section{Referências}

BEISIEGEL, Celso de Rui. Cultura do povo e educação popular. In: VALLE, Edênio; QUEIROZ, José J. de (Org.). A cultura do povo. São Paulo: Cortez, 1979. 
BEISIEGEL, Celso de Rui. Ensino público e educação popular. In: PAIVA, Vanilda (Org.). Perspectivas e dilemas da educação popular. 2. ed. Rio de Janeiro: Graal, 1986.

BRANDÃO, Carlos Rodrigues; ASSUMPÇÃO, Raiane. Cultura rebelde: escritos sobre a educação popular ontem e agora. São Paulo: Editora e Livraria Instituto Paulo Freire, 2009.

BRANDÃO, Carlos Rodrigues. A questão política da educação popular. 6. ed. São Paulo: Brasiliense, 1986.

CALADO, Alder Júlio Ferreira. Reproblematizando o(s) conceito(s) de educação popular. In: COSTA, Marisa Vorraber (Org.). Educação popular hoje. São Paulo: Loyola, 1998.

FÁVERO, Osmar (Org.). Cultura popular e educação popular: memórias dos anos 60 . Rio de Janeiro: Graal, 1983.

FREIRE, Paulo. Pedagogia do oprimido. 50. ed. Rio de Janeiro: Paz e terra, 2011.

FREIRE, Paulo. Educação como prática da liberdade. 28 ed. São Paulo: Paz e Terra, 2005.

MARTINS, José de Souza. Exclusão social e a nova desigualdade. 4. ed. São Paulo: Paulus, 2009.

MELO NETO, José Francisco de. Educação popular e experiência. Caxambu - MG: Anped, 2010. Disponível em http://33reuniao.anped.org.br/. Acesso em: 20 outubro 2016.

PAIVA, Vanilda. História da educação popular no Brasil: educação popular e educação de adultos. 6. ed. São Paulo: Loyola, 2003.

PAIVA, Vanilda (Org.). Perspectivas e dilemas da educação popular. 2 ed. Rio de Janeiro: Graal, 1986.

PALUDO, Conceição. Educação popular: dialogando com redes latino-americanas (20002003). In: PONTUAL, Pedro; IRELAND, Timothy (Org.). Educação popular na América Latina: diálogos e perspectivas. Brasília: MEC/Unesco, 2009.

STRECK, Danilo. Territórios de resistência e criatividade: reflexões sobre os lugares da Educação Popular. In: STRECK, Danilo; ESTEBAN, Maria Teresa (Org.). Educação popular: lugar de construção social coletiva. Petrópolis: Vozes, 2013.

WANDERLEY, Luiz Eduardo. Educação popular: metamorfoses e veredas. São Paulo: Cortez, 2010.

WEFFORT, Francisco. Educação e política: reflexões sociológicas sobre uma pedagogia da liberdade. In: FREIRE, Paulo. Educação como prática da liberdade. 15 ed. Rio de Janeiro: Paz e Terra, 2013. 
$D r^{a}$ Kergilêda Ambrosio de Oliveira Mateus

Universidade Estadual do Sudoeste da Bahia - Brasil

Doutora em Educação

Departamento de Ciências Humanas, Educação e Linguagem - DCHEL

Grupo de Pesquisa: Práticas Sociais e Processos Educativos

E-mail: kmatteus@hotmail.com

Dr $^{a}$ Aida Victória Garcia Montrone Universidade Federal de São Carlos - Brasil

Doutora em Educação

Departamento de Metodologia de Ensino

Grupo de Pesquisa: Práticas Sociais e Processos Educativos

E-mail: montroneufscar@gmail.com

Recebido em: 28 de novembro de 2016

Aprovado em: 23 de dezembro de 2016 